\title{
Multidrug-Resistant Tuberculosis in Portugal: Patients' Perception of the Challenges Faced during Treatment
}

\author{
Marcela Bhering ${ }^{a, b}$ Vicente Sarubbi Junior ${ }^{c}$ Afrânio Kritski ${ }^{a}$ \\ Fabiana Barbosa Assumpção Souza ${ }^{d}$ Raquel Duarte ${ }^{e, f}$ \\ ${ }^{a}$ Academic Tuberculosis Program, School of Medicine, Federal University of Rio de Janeiro, Rio de Janeiro, Brazil; \\ bProfessor Hélio Fraga Reference Centre, Sergio Arouca National School of Public Health, Oswaldo Cruz Foundation,

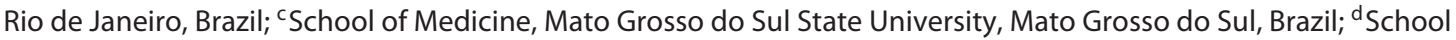 \\ of Nursing, Federal University of Rio de Janeiro State, Rio de Janeiro, Brazil; 'EPIUnit, Public Health Institute, \\ University of Porto, Porto, Portugal; ${ }^{\mathrm{f} P u b l i c}$ Health Science and Medical Education Department, School of Medicine, \\ University of Porto, Porto, Portugal
}

\section{Keywords}

Tuberculosis · Multidrug-resistant tuberculosis · Qualitative research $\cdot$ Social stigma $\cdot$ Needs assessment $\cdot$ Professionalpatient relations $\cdot$ Patient compliance $\cdot$ Patient care $\cdot$ Social support

\footnotetext{
Abstract

Introduction: The increase in drug-resistant tuberculosis (TB) threatens global progress in eliminating TB, and constitutes a major challenge for patients, health-care workers and health services. Treatment for multidrug-resistant TB (MDRTB) can last almost 2 years, and is more expensive, more toxic, and less effective than treating TB caused by drug-sensitive bacilli. This study aims to analyze patients' narratives about the challenges they face during MDR-TB treatment and identify the support factors that help patients being treated in the most populous district of Portugal. Methods: Semi-structured interviews were conducted with patients
}

being treated for MDR-TB. The interviews were coded using thematic analysis. They were audio-recorded, transcribed, and transported into NVivo v12 for data management and coding. Results: Depression, social discrimination, and the side effects of drugs are the main challenges faced by patients with MDR-TB. A good relationship of the patients with the health team, emotional support, and supervised treatment stand out as the factors that generate better adherence and treatment success. Conclusion: In addition to modern diagnostic techniques and new treatments, MDR-TB can be fought by focusing on the care and needs of patients. We suggest that the Lisbon Tuberculosis Program adopts the following measures: build the health-care team's capacity to identify symptoms of depression early, increase public awareness of the disease, expand the multidisciplinary team, and expand the options for individualized social support for patients. (c) 2020 The Author(s). Published by S. Karger AG, Basel on behalf of NOVA National School of Public Health karger@karger.com www.karger.com/pjp

Karger $\stackrel{\text { ' }}{5}$

BOPEN ACCESS (c) 2020 The Author(s). Published by S. Karger AG, Basel on behalf of NOVA National School of Public Health

This article is licensed under the Creative Commons AttributionNonCommercial-NoDerivatives 4.0 International License (CC BYNC-ND) (http://www.karger.com/Services/OpenAccessLicense) Usage and distribution for commercial purposes as well as any distribution of modified material requires written permission.
Marcela Bhering

Faculdade de Medicina da Universidade Federal do Rio de Janeiro Rua Prof Rodolpho Paulo Rocco, 255/6o

Rio de Janeiro, 21941-913 RJ (Brazil) marbhering@gmail.com 
Tuberculose multirresistente em Portugal: percepção dos pacientes sobre os desafios enfrentados durante o tratamento

\section{Palavras Chave}

Tuberculose · Tuberculose multirresistente · Investigação qualitativa · Estigma social · Avaliação de necessidades . Relação profissional-doente · Assistência ao paciente · Apoio social

\section{Resumo}

Introdução: $\mathrm{O}$ aumento da TB resistente aos medicamentos ameaça o progresso global em direção às metas de eliminação da TB e representa um grande desafio para pacientes, profissionais de saúde e serviços de saúde. $\mathrm{O}$ tratamento da tuberculose multirresistente (TB-MDR) pode durar quase dois anos, sendo mais caro, mais tóxico e menos eficaz do que a TB em bacilos sensíveis a medicamentos. Este estudo tem como objetivo analisar as narrativas dos pacientes sobre os desafios que enfrentam e identificar os fatores de suporte oferecidos durante o tratamento num distrito de Portugal. Métodos: Foram realizadas entrevistas semiestruturadas com pacientes em tratamento para tuberculose multirresistente. As entrevistas foram codificadas por meio de análise temática. Foram gravadas em áudio, transcritas e transportadas para o NVivo versão 12 para e codificação de dados. $\boldsymbol{R e}$ sultados: Os resultados revelaram que depressão, discriminação social e os efeitos colaterais dos medicamentos são os principais desafios enfrentados pelos pacientes com TB-MDR. Um bom relacionamento dos pacientes com a equipa de saúde, apoio emocional e tratamento supervisionado destacam-se como fatores que geram melhor adesão e sucesso no tratamento. Conclusão: Além das modernas técnicas de diagnóstico e novos tratamentos, a tuberculose multirresistente pode ser combatida enfatizando-se o atendimento e as necessidades do paciente. Assim, sugerimos que o programa de tuberculose de Lisboa adote as seguintes medidas: possibilitar à equipa de saúde o reconhecimento precoce dos sintomas de depressão, aumentar a conscientização pública sobre a doença, ampliar a equipa multidisciplinar e ampliar as possibilidades de apoio social individualizado aos pacientes. Descritores: Tuberculose Multidroga Resistente; Pesquisa Qualitativa; Assistência ao Paciente; Apoio Social.

(c) 2020 The Author(s). Published by S. Karger AG, Basel on behalf of NOVA National School of Public Health

\section{Introduction}

Tuberculosis (TB) is one of the top 10 causes of death worldwide and the leading cause among infectious diseases. Its control has been weakened by the increase of cases with resistance to rifampicin and isoniazid, the main treatment drugs [1].

Multidrug-resistant TB (MDR-TB) is defined as TB with resistance to at least rifampicin and isoniazid. Extensively resistant TB (XDR-TB) is increased by resistance to $\geq 1$ fluoroquinolone and at least $1 / 3$ second-line injectable drugs used to treat TB (capreomycin, kanamycin, and amikacin) [2].

Treatment for MDR/XDR-TB can last almost 2 years and is more expensive, more toxic, and less effective than treating TB caused by drug-sensitive bacilli [3]. Moreover, a patient with MDR and comorbidities, such as human immunodeficiency virus (HIV), takes 20 tablets and 1 injectable drug daily which, in turn, reduce a patient's compliance and quality of life, making treatment management difficult for the health-care team [4].

In Portugal, despite the significant reduction in TB indicators in the last decade, TB is still a public health problem. Most of the TB cases occur in the districts of Lisbon and Porto [5].

This study aims to analyze patients' narratives about the challenges they face during the treatment of MDR-TB and XDR-TB and identify the support factors that help them.

\section{Methods}

This was a qualitative descriptive study with purposive sampling. The Consolidated Criteria for Reporting Qualitative Research (COREQ) were applied to ensure study rigor [6].

Research was conducted at tuberculosis outpatient units (CDP), which are reference units for the diagnosis, treatment, and prevention of TB and MDR/XDR-TB in Lisbon and the Tagus Valley region (LVT).

Participants older than 18 years who were undergoing treatment for MDR/XDR-TB and spoke and understood Portuguese were included. Participants who were not living in the Lisbon District, and those with serious mental illness or cognitive limitations were excluded.

Data were collected through semi-structured interviews conducted between November 2017 and May 2018. The interviews were conducted using an original script that drew on the available literature and group discussions. We did 2 pilot interviews-and revised the interview guide. Before each meeting, the researcher explained the content and purpose of the interview to the interviewees. All the interviews were conducted individually and face- 
Table 1. Content analysis procedures that describe in detail the pathway adopted by researchers in the process

1st Level:

Preanalysis
Rules for the composition of the material.

Relevance rule: the research material must be a source of information that corresponds to the research objective. Representativeness rule: the material coming from the research subjects should assist in elucidating the studied phenomenon. Homogeneity rule: the material gathered must comply with the selection criteria that allow a cohesive analysis and make it possible to draw approximations and distances in the reading and analysis of the results found.

Exhaustiveness rule: defined textual corpora, all material must be included and read through floating reading.

The reading should cover the entire corpora, leaving the impressions that will guide the researcher to point out the sources for the detailed exploration of the material.

2nd Level: Inserting the material in the NVivo

Exploration of material v12 software for data exploration.

The inferential process in which data are read, systematically explored, described, and brought together through 3 units of analysis.
Context unit: extended text segments that make it possible to contextualize the textual clippings (records for analysis). Registration unit: they are in themselves what characterizes the cut of the analyzed content emblematically.

Sense units: units described by the systematic analysis of the recording units; the first inferential level that allows the researcher to create the empirical categories that emerge from the analyzed corpora.

Systematic and objective procedures that make it possible to turn the empirical categories into analytical categories.

The second inferential level occurs (inductive-deductive), with the interpretation of the analytical categories and arguments anchored in the theoretical framework. to-face by the first author, and audio-recorded. Theoretical saturation was used as a criterion for interrupting further interviews [7]. All interviews were transcribed verbatim using anonymous participant identifiers.

The interview guide was composed of 2 parts. The first part has structured questions about the clinical and demographic variables: sex, age, country of origin, date of beginning the treatment, marital status, number of people residing at his/her residence, years of study, occupational status, monthly household income, type of residence (own/rent/municipal housing), location of residence, HIV status, previous treatment for TB, other TB cases in the family, and drug resistance category. The second part has questions about the disease history, knowledge, experiences, and feelings of the patient in relation to his/her treatment.

The analysis was conducted according to the thematic content analysis stages: pre-analysis, exploration, data analysis process, and interpretation (Table 1) [8]. The software Nvivo v12 was used to code and cross-reference themes with participant characterization data. The themes were derived from interviews and were discussed by 3 researchers until unanimity was reached. Participants' clinical and demographics were analyzed by means of descriptive statistics.

\section{Results}

Twenty patients were treated at the CDP in the study period. Nine participants were invited; 8 agreed to participate in the interview and 1 was excluded due to cognitive limitations. The patients were interviewed until theoretical saturation occurred. There were 5 males and $3 \mathrm{fe}-$ males aged between 21 and 63 years (median 45 years). The group of interviewees was composed of 6 people of Portuguese origin, 1 of Angolan descent, and 1 of Cape Verdean origin. Patients were at different stages of treatment, i.e., varying from the 4 th to the 21 st month.

Regarding marital status, $4(50 \%)$ were married or living in a stable union, and $5(62.5 \%)$ lived with $\geq 5$ people in the same residence. Only 1 patient lived alone. All patients had some level of education, ranging from the 4 th grade to technical courses.

As for occupational status, 3 were on social security (a domestic, a cleaning professional, and a panel beater), 1 was a student, and 4 were unemployed. The monthly household income was, at the most, the minimum wage, and only 1 had no income. 


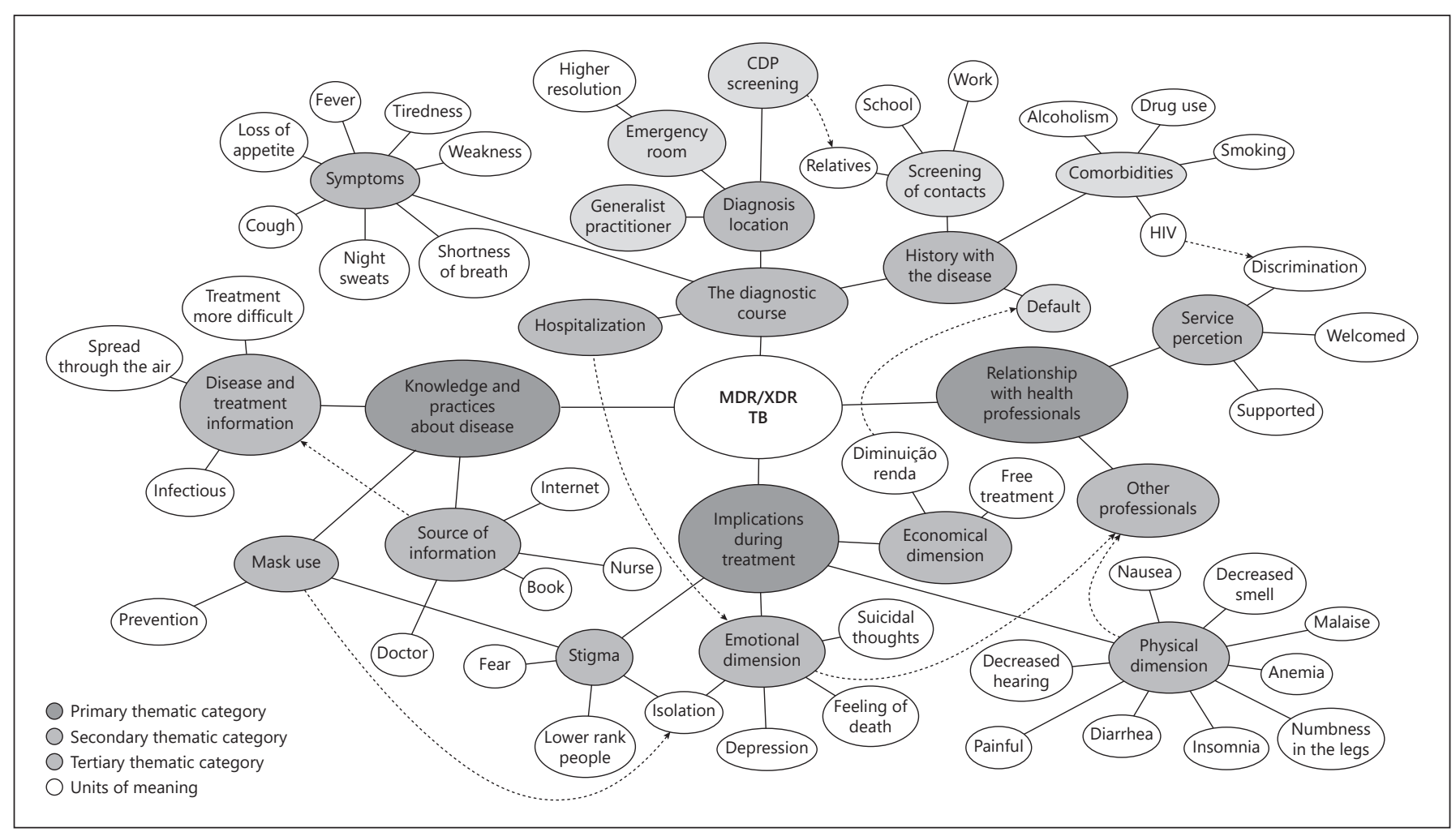

Fig. 1. Thematic categories, units of meaning, and their relations.

Portugal has a housing policy whereby municipalities offer rental properties to low-income families at prices lower than the official market. Of the patients interviewed, 3 lived in publicly owned houses. Sintra was the most common place of residence (5 patients; 62.5\%). Only 2 patients had a previous history of $\mathrm{TB}$, and the other 6 had other cases of TB in their families during the interview period. Two patients had HIV coinfection and 2 had XDR-TB.

The thematic content analysis of the interviews made it possible to structure a tree of thematic nodes. From the thematic-categorical analysis framework, it was possible to structure a discussion based on 4 thematic categories that address the patient's experience during treatment, knowledge about the disease, the relations established with the health professionals, and the consequences of the disease and treatment.

The primary, secondary, and tertiary thematic categories, and the units of meaning are displayed in Figure 1. The dotted arrows seek to establish, in a more dynamic way, the relationships between the themes and units of meaning. From this, it is clear that the themes are not static, and that they influence $>1$ of the issues highlighted.
The diagnostic course category encompassed the reported symptoms, adverse events until diagnosis, hospitalization, and behaviors that advanced or delayed the initial process of disease development and treatment.

Among the symptoms, most patients (62.5\%) reported tiredness or weakness as the most striking symptom, followed by cough (50\%) and loss of appetite/weight loss, shortness of breath/difficulty breathing, fever, and night sweats (25\% each).

Five $(62.5 \%)$ patients were diagnosed in the hospital. Two had previously sought health care, but the diagnosis was allergic cough and flu. When the condition of one patient persisted, he reported that he had gone to the health unit, but after the worsening of his clinical condition, he resorted to the hospital emergency room.

In this study, we observed that requiring immediate resolution of their health problems was the crucial factor that led patients to seek medical care.

As for hospitalization, although there is no legal norm in Portugal, it is recommended that patients resistant to multiple drugs remain hospitalized until the direct sputum examination is negative in 3 consecutive samples. Hospitalization is proposed to the patient, but not im- 
posed; if they do not want to be hospitalized, the healthcare team goes to their home. Of the 8 patients interviewed, 6 (75\%) were hospitalized.

Regarding the history of the disease, the statements referring to contact screening, comorbidities, and previous nonadherence were categorized. In total, 7 (87.5\%) patients reported that relatives or colleagues from school or work had undergone TB screening. Six (75\%) patients had relatives with MDR-TB.

The most-reported comorbidities were alcoholism (37.5\%) and smoking (12.5\%). Two patients were employed in the construction industry. They attributed possible contagion to the habit of sharing drink bottles and smoking cigars.

Two patients reported having had drug-sensitive TB, 1 of whom stopped his TB and AIDS treatment because he thought he was already better.

I was feeling good. I never worried about these treatment things, and I wasn't caring about these treatment things, these things... After first tuberculosis I got, I was fine, feeling good... I went back to work; only then, I stopped doing HIV treatment. (PAC2)

The knowledge and practices about the disease category made it possible to identify the level of information patients have about the disease and how it may affect treatment. All patients proved to have some degree of knowledge about the disease. The most prevalent information was that $\mathrm{TB}$ is an airborne disease $(63.5 \%)$ and is infectious (50\%), and that MDR-TB treatment is more difficult than that for TB caused by drug-sensitive bacilli (50\%).

I know it's multiresistant, it's the strongest of all. It's harder to treat, right, this is not simple. The nurse told me that a "bug" (bacillus) made a small bag inside the lung that, after treatment, it was still there. That's why treatment takes so long to make sure you even get the "bug" inside. (PAC1)

Regarding the source of information about the disease, $6(75 \%)$ patients received this from the health-care team and $2(25 \%)$ reported having researched it via books and the Internet. During hospitalization, respondents said that the nursing staff focused on health education to inform them about TB.

All patients underwent supervised treatment. In the initial phase, where injectable medications are used, when the patient was not hospitalized, the nursing staff performed home visits. In the oral medication phase, 4 (50\%) patients reported going to the health unit daily to take the medication. Three patients (37.5\%) received daily home visits from the health-care team. One (12.5\%) patient with walking difficulties, had to have the medication given to their mother who was also responsible for supervision.

The nurses at the health center kept the medicine, and they went there [at the patient's house] to make me take medicine every day... and they had to watch me take it, and I got an injection every day... That was six months, always like this. Injections (PAC1)

The use of a face mask appeared in the reports of 4 (50\%) patients as an instrument associated with the prevention of disease transmission.

Imagine they are all there on the transport. People are all coughing and breathing. So, the mask is to protect us and not to contaminate anyone. Even the Chinese wear a mask. People look a little but don't stare... (PAC6)

The relationship with the health professionals has to do with patients' feelings during treatment. Overall, 7 $(87.5 \%)$ patients said they had felt welcomed by the health-care workers. Three $(37.5 \%)$ stressed that they would not have been able to perform the treatment had it not been for the support and constant presence of the professionals.

If I had not had the nurse, I would not have made it, and it's tough two or three days, then it is hard to come down... But after a week it was hard... If the nurse wasn't there every day, saying I have to take it, go slow because it was about ten or so and big. And then she would say one at a time, swallowing. And then only when I was done, she went away. She had to see me taking all [medicines]. If there wasn't someone there supporting me, I don't think anyone can do it on their own. (PAC1)

In turn, $1(12.5 \%)$ patient said she had felt discriminated against for having HIV.

Sometimes there is a doctor who has a heart...but not all have it. It's like in hospitals. Not everyone sees a person who has HIV with kind eyes. But a health professional should not do this... but many are indifferent. They say discrimination doesn't exist; that's what they say. Do you think not? (PAC2)

At CDP, the health team is composed only of doctors and nurses. Four patients (50\%) reported that they needed the help of other professionals to solve problems directly or indirectly linked to the disease. Two required a social worker to assist with benefit-related issues. Two patients required a psychologist to treat depression, 1 a psychiatrist to treat addiction, and 1 a physiotherapist to treat swelling and pain in the lower limbs due to the side effects of the medication.
Bhering/Sarubbi Junior/Kritski/Souza/ Duarte 
The indications of the treatment category made it possible to identify how the patient was affected during the treatment, either emotionally or physically as well as including statements that reflected the stigma of the disease. In this sense, TB appeared to be associated with "fear" and as a disease of "lower rank people." Half of the patients reported that only family and close friends had known about the disease, and that they hid the fact that they were sick from neighbors. The association of the disease with death was also present in the narrative of $3(37.5 \%)$ patients.

I know that tuberculosis is a disease that kills. And you can pass it on to other people. I know it's a dangerous disease because in the past many people died from it. (PAC1)

The use of a face mask appeared as a stigma when a patient asked the professionals to allow him or her to put on the mask only when they entered his or her home.

At first, they [nurses] went there wearing a mask [at the patient's house]. They were wearing a mask, and my neighbors would comment, and they came to ask what it was. I never told them what it was. I don't have to say, right?! And then there was a time when I asked them just to wear the mask at the entrance [after entering the patient's home]. (PAC6)

Six $(75 \%)$ patients reported emotional difficulties. The length of stay in isolation was considered extremely difficult by $3(37.5 \%)$ patients who described the difficulty of being secluded for long periods as a feeling of impending death, deep sadness, and suicidal thoughts.

Regarding the physical dimension of treatment, the main adverse events described by the patients were the following: malaise (75\%), nausea, loss of appetite $(62.5 \%$ each), numbness in the legs (37.5\%), and anemia (37.5\%). Treatment was reported to be painful and exhausting by patients as well as causing severe physical limitations.

Then, following the injection, the person is in such a bad state that afterward, it is difficult for a person to move there for a long time... Because the injection is strong and painful... It has to be given very slowly for us to feel... If the nurse doesn't know how to do the injection, it's too fast, and it hurts a lot. And then you must get some rest... (PAC3)

Regarding the treatment and its costs, in Portugal, the health system works on the basis of coparticipation, i.e., some is paid by the patient. However, for public health diseases, treatment and additional tests are completely free. No patient reported having difficulty doing the tests or there being a lack of medication during treatment.

\section{Discussion}

The narrative of the journey from symptoms, to diagnosis, to adverse events associated with treatment, can provide a broader view of the available resources and the difficulties faced by MDR-TB patients in Lisbon.

It should be noted that it was the symptoms of TB that made the patients seek medical help. Diagnoses were made at GP practices or at the hospital where there are specialists. Although most of the patients interviewed went to their GP, 2 patients went to hospital because of their worsening clinical condition and were then diagnosed.

In recent years, there has been an expansion of the primary health-care network designed to assign family health-care teams to all people living in Portugal. Between 2010 and 2017, the percentage of the Portuguese population assigned a family doctor went from 85.8 to 92.7\%. Despite this increase, the LVT region has the lowest coverage in the country, $82.5 \%$ [9]. Nevertheless, the hospital network is half an hour away from any home; this, in turn, facilitates access to emergency appointments for people residing in the LVT region [10].

In the basic health unit, 2 patients received a first diagnosis of flu and allergic cough. A study conducted in Portugal found an average time span of 33 days between symptom onset and first contact with the health service. The same study also found a 17-day period between the patient's first contact with the health service and the beginning of treatment. In total, the median was 68 days between symptom onset and treatment onset [11]. Reducing the time to diagnosis, primarily by continuous training of TB professionals, has been one of the challenges of disease control faced by the country [5].

After diagnosis, cases with positive smear are hospitalized. This was the case for most of the patients interviewed. In Portugal, in addition to cases associated with disease severity and social issues, hospitalization is recommended for cases of contagious-stage MDR-TB. Although there are no legal mechanisms that oblige the patient to undergo treatment, none of the respondents questioned this measure. On the one hand, hospitalization in the contagion period is a way of preventing the spread of the disease. On the other, it can cause physical and emotional damage to some patients.

Hospitalization involves isolating the patient, sometimes for several months. This was very difficult for patients. Prolonged isolation was associated with a feeling of impending death, deep sadness, and suicidal thoughts. A study of hospitalized MDR-TB patients found that $26 \%$ 
of them had symptoms of depression and/or anxiety [12]. Another study of 45 patients with MDR-TB and HIV coinfection indicated that $16 \%$ had symptoms of depression [13].

In addition, some of the drugs used to treat MDR-TB can cause psychiatric disorders such as psychosis and depression [14]. Teams involved in treating MDR-TB patients should be trained to apply appropriate mental health assessment tools, especially early on, so that psychiatric disorders can be identified as soon as possible [13].

Moreover, patients on MDR-TB treatment may commonly experience the symptoms of stigma, discrimination, and psychological distress [14]. In our work, the social stigma can be confirmed by the fact that most patients did not tell their friends and acquaintances about the disease. The face mask also appeared in interviews as a symbol of social stigma, because while protecting the patient, it also exposes the disease. In the contagion period, patients should wear a mask if they come into contact with other people. The patients interviewed preferred to be more secluded. This voluntary isolation may be the result of a feeling of self-discrimination, which leads the patient to anticipate the isolation that society will impose on them [15].

Only of the patients with HIV coinfection expressed feeling they were discriminated against. Like TB, HIV is stigmatized in this context because it is linked to other undervalued characteristics, which are also social determinants of health. TB can also be perceived as a marker of HIV positivity in areas of high disease prevalence. Therefore, HIV-associated stigma can also be transferred to individuals infected with TB [16].

Stigma is one of the most common barriers in the fight against tuberculosis. Among the causes are the associations of TB with poverty, malnutrition, immigrant status, and lower social class [16]. Even though stigma is often viewed as natural, intractable, or easily overcome with an overall improvement in the quality of or access to health services, it must be identified and addressed with educational measures [17].

Although treatment failure is the central hypothesis regarding the development of resistance to multiple drugs, only 2 patients reported having had previous TB treatment and only 1 defaulted. In Lisbon, the predominance of primary infection can be explained by the endemic circulation of MDR strains of TB [18].

In our study, there was a high intrahousehold transmission rate. Of the 8 patients interviewed, 6 had family members with MDR-TB. All patients, however, reported that family members and other contacts had been called to the CDP for disease and infection screening. Recent studies conducted in Portugal, combining a strain genotyping analysis with epidemiological data from MDR-TB cases, have confirmed strong epidemiological links [19].

Nonadherence to treatment was not a recurring problem in the sample studied. Only 1 patient abandoned his previous treatment, claiming he had felt better and needed to go back to work. Understanding the disease itself and its consequences is vital for the patient to acknowledge the importance of maintaining treatment [20]. We observed that the patients were aware of the transmission of the disease and the greater difficulty of treating MDR cases. In our analysis, it was possible to verify that some patients researched the disease themselves, in books and on the Internet, but most cited the health-care team as the source of information. On the basis of the communication with the health professional, patients build ideas around their diagnosis and treatment [21]. The perception of the disease itself and the importance of treatment depend on receiving the correct information, and so there must be a good relationship between the patient and the health-care team [22].

In Portugal, TB treatment is free, which contributes to improving treatment adherence, but that alone is not enough. As a strategy for TB control, all patients undergo directly observed treatment (DOT) and, at the CDP in Lisbon, they receive transport tickets for their appointments. The patients in our sample highlighted that the most important factor for the continuity of treatment was the support provided by the health-care team. The interviewees were satisfied with the team, emphasizing that their support had been essential for the continuity of treatment, especially in the first phase of the scheme which includes drug injections as well as taking a large number of pills. DOT can provide the patient with a moment to express their doubts and problems and allow the health professional to identify other needs, thereby strengthening the continuity of treatment [23].

Finally, treatment for MDR-TB is long and painful, with a high frequency of adverse events [24]. Second-line medications are often associated with adverse events, ranging from mild to fatal, requiring temporary or permanent drug discontinuation [25]. In our study, adverse events were reported by $87.5 \%$ of the patients interviewed. The patients said they had had careful clinical follow-up, and that, when necessary, had been referred to other specialists. Although there was no multidisciplinary team at the CDP, patients were referred to specialized services when needed. Even a high proportion of adverse events
68

Port J Public Health 2020;38:62-70 DOI: $10.1159 / 000511198$
Bhering/Sarubbi Junior/Kritski/Souza/ Duarte 
which sometimes disrupted routine activities, did not prevent the continuity of treatment.

Some limitations of our work should be acknowledged. Before the interviews, we tried to encourage patents to relax and we provided them with opportunities to express their thoughts. Health professionals were not present during the interviews, but then again, someone in a position of authority can also deter patients talking openly. Although this study has a small sample that does not necessarily represent the perceptions of all patients, it is a starting point for identifying patients' needs and expectations during TB treatment.

\section{Conclusion}

This study showed that depression, social discrimination, and side effects of drugs were challenges faced by patients with MDR-TB. Nevertheless, the good relationship of patients with the health team and supervised treatment were factors found to be relevant for better adherence to treatment. This finding indicates that it is key that health services acknowledge and tackle patients' emotional and social needs during treatment.

Suggestions for future interventions include building health team capacity to identify symptoms of depression early, increasing public awareness of the disease, expanding the multidisciplinary team at the CDP, and increasing the possibilities of individualized social support for patients. In addition, it is important to investigate whether patients' perceptions vary with time, age, support, and treatment stage. Likewise, it is also key to analyze what are the moderating or mediating impact of variables that could mitigate the effects of treatment on patients.

\section{Acknowledgements}

We thank the LVT Regional Reference Centre for MDR-TB and the Department of Public Health of the ARSLVT. Our very special thanks to all the professionals at CDP LVT, especially Dr Maria da Conceição Gomes, Dr Carlos Gomes, nurse Isabel Louro and nurse Cristina Figueiredo.

\section{Statement of Ethics}

The Ethics Committee for Health of Lisbon and Tagus Valley Region Health Administration approved the study (ref. 11101/ CES/2017). All participants were fully informed about the content of the study. The voluntary and confidential nature of the study was stressed, and the participants had the right to withdraw from the study at any time. In addition, the fact that refusal or withdrawal from the study would not influence the care the patients received was also emphasized. Verbal and written informed consent were obtained before the interviews.

\section{Conflict of Interest Statement}

The authors have no conflicts of interest to declare.

\section{Funding Sources}

This project was performed without funding.

\section{Author Contributions}

M.B., A.F., and R.D. conceptualized and designed the study; V.S. contributed to the study methodology and interpretation of results; M.B., V.S.J., and F.B.A.S. contributed to qualitative analysis; M.B. handled the database, did the data collection, and wrote the manuscript. All authors critically reviewed the paper and read and approved the final version.

\section{References}

1 WHO. Global Tuberculosis Report 2018. Geneva: World Health Organization; 2018.

2 WHO. Drug resistant-TB, surveillance and response: supplement Global Tuberculosis Report 2014. Geneva: World Health Organization; 2014.

3 Samuels JP, Sood A, Campbell JR, Khan FA, Johnston JC. Comorbidities and treatment outcomes in multidrug-resistant tuberculosis: a systematic review and meta-analysis. Sci Rep. 2018;8(1):4980.

4 Dudnyk A, Burman M, Kulyk L, Rzhepishevska O. M/XDR-TB treatment perspective: how to avoid mountains of pills via digital technologies. Respirology. 2018;23(6):636-7.
5 Franco I, Sousa P, Gomes M, Oliveira A, Gaio AR, Duarte R. Social profile of the highest tuberculosis incidence areas in Portugal. Rev Port Pneumol. 2016;22(1):50-2.

6 Tong A, Sainsbury P, Craig J. Consolidated criteria for reporting qualitative research (COREQ): a 32-item checklist for interviews and focus groups. Int J Qual Health Care. 2007;19(6):349-57.

7 Fontanella BJ, Luchesi BM, Saidel MG, Ricas J, Turato ER, Melo DG. Sampling in qualitative research: a proposal for procedures to detect theoretical saturation. Cad Saude Publica. 2011;27(2):389-94.
8 Bardin L. Análise de conteúdo. Lisboa: Edições 70; 2011.

9 Retrato da saúde, Portugal. Lisboa: Ministério da Saúde; 2018

10 Cabral MV, Silva PA. O estado da saúde em Portugal: acesso, avaliação e atitudes da população portuguesa em relação ao sistema de saúde, evolução entre 2001 e 2008 e comparações regionais. Lisboa: Imprensa de Ciências Sociais; 2009

11 Zão I, Ribeiro AI, Apolinário D, Duarte R Why does it take so long? The reasons behind tuberculosis treatment delay in Portugal. Pulmonology. 2019;25(4):215-22. 
12 Aydin IO, Uluşahin A. Depression, anxiety comorbidity, and disability in tuberculosis and chronic obstructive pulmonary disease patients: applicability of GHQ-12. Gen Hosp Psychiatry. 2001;23(2):77-83.

13 Das M, Isaakidis P, Van Den Bergh R, Kumar AM, Nagaraja SB, Valikayath A, et al. HIV, multidrug-resistant $\mathrm{TB}$ and depressive symptoms: when three conditions collide. Glob Health Action. 2014;7(1):1-5.

14 Thomas BE, Shanmugam P, Malaisamy M, Ovung S, Suresh C, Subbaraman R, et al. Psycho-socio-economic issues challenging multidrug-resistant tuberculosis patients: a systematic review. PLoS One. 2016; 11(1):e0147397.

15 Rodrigues IL, Souza MJ. Representações sociais de clientes sobre a tuberculose: desvendar para melhor cuidar. Esc Anna Nery. 2005 Apr;9(1):80-7.

16 Courtwright A, Turner AN. Tuberculosis and stigmatization: pathways and interventions. Public Health Rep. 2010;125(4):34-42.
17 Baral SC, Karki DK, Newell JN. Causes of stigma and discrimination associated with tuberculosis in Nepal: a qualitative study. BMC Public Health. 2007;7(1):1-10.

18 Bhering M, Kritski A, Nunes C, Duarte R. Multidrug-resistant tuberculosis in Lisbon: unsuccessful treatment and associated factors, 2000-2014. Int J Tuberc Lung Dis. 2019; 23(10):1075-81.

19 Oliveira O, Gaio R, Carvalho C, CorreiaNeves M, Duarte R, Rito T. A nationwide study of multidrug-resistant tuberculosis in Portugal 2014-2017 using epidemiological and molecular clustering analyses. BMC Infect Dis. 2019;19(1):1-10.

20 Chirinos NE, Meirelles BH. Fatores associados ao abandono do tratamento da tuberculose: uma revisão integrativa. Texto Contexto Enferm. 2011;20(3):399-406.
21 Munro SA, Lewin SA, Smith HJ, Engel ME, Fretheim A, Volmink J. Patient adherence to tuberculosis treatment: a systematic review of qualitative research. PLoS Med. 2007; 4(7):e238

22 Oliveira JF, Antunes MB. Abandono anunciado ao tratamento da tuberculose em uma unidade de saúde da família do Recife: a perspectiva do usuário. Rev APS. 2012;15:4-13.

23 Queiroz EM, Ferreira KR, Bertolozzi MR. Tuberculose : limites e potencialidades do tratamento supervisionado. Rev Lat Am Enfermagem. 2012;20(2):8.

24 Günther G, Van Leth F, Alexandru S, Altet N, Avsar K, Bang D, et al. Clinical management of multidrug-resistant tuberculosis in $16 \mathrm{Eu}$ ropean countries. Am J Respir Crit Care Med. 2018;198(3):379-86.

25 Arbex MA, Varella MC, Siqueira HR, Mello FA. Antituberculosis drugs: drug interactions, adverse effects, and use in special situations: Part 2: second-line drugs. Aust Libr J. 1986;35(1):53-4 